\title{
OS PROCESSOS ESPACIAIS DE CONCENTRAÇÃO E CENTRALIZAÇ̃̃O DAS ATIVIDADES URBANAS E DO CAPITAL NA METRÓPOLE RIO: UMA PERSPECTIVA PARA A COMPREENSÃO DA PRODUÇÃO CONTEMPORÂNEA DO ESPAÇO
}

\author{
Los procesos espaciales para la concentración y centralización de actividades urbanas y de capital \\ en el metropolo de Río: una perspectiva para entender la producción contemporánea de espacio
}

\section{the space processes for concentration and centralization of urban activities and capital in Rio Metropole: a perspective for understanding contemporary production of space}

Les processus spatiaux de concentration et de centralisation des activités urbaines et capitales dans le métropole Rio: perspectives de comprendre la production contemporaine de l'espace

\author{
Juliana Luquez \\ Doutora em Geografia Humana pela USP; Professora da UEMS \\ julianaluquez@usp.br
}

Artigo enviado para publicação em 08/05/2019 e aceito em 02/10/2019

DOI: $10.12957 /$ tamoios.2019.34930

\begin{abstract}
Resumo
O último quartel do século XX e as quase duas décadas do século XXI compreendem o intervalo de tempo no qual é possível perceber com bastante clareza as intensas transformações socioespaciais pelas quais os espaços metropolitanos vêm passando dada a intensificação das dinâmicas dos processos em curso. A relação dos processos socioespaciais com a produção do espaço merece novo destaque nas pesquisas sobre a metrópole e sua região, pois é na análise das implicações desses processos que alcançamos possíveis compreensões sobre as complexidades da nova configuração metropolitana. Elegemos para a análise desta problemática os processos de concentração e centralização da dinâmica territorial das atividades urbanas na área metropolitana - dispersa e fragmentada - e a lógica de produção do espaço. Este trabalho tem como objetivo compreender as novas dimensões da lógica de produção do espaço na Metrópole Rio a partir da perspectiva teórica dos conceitos de concentração e centralização do capital e das atividades urbanas. A análise gravitará na relação entre a dinâmica territorial das atividades que dinamizam a produção do espaço e as implicações destas no processo de reestruturação metropolitana. Para tanto, buscaremos examinar algumas hipóteses e considerações apresentadas por pesquisadores que vêm debruçando-se sobre a problemática desses processos em áreas metropolitanas a fim de contribuir para o entendimento das complexidades das metrópoles contemporâneas e suas novas características anunciadas através desses processos em curso e colocados aqui em nossa lente de aumento.
\end{abstract}

Palavras-Chave: Concentração, centralização, atividades urbanas, produção do espaço, Metrópole Rio.

\section{Resumen}

El último cuarto del siglo XX y las casi dos décadas del siglo XXI comprenden el marco temporal en el que es posible ver muy claramente las intensas transformaciones socioespaciales por las que han pasado los espacios metropolitanos dada la intensificación de la dinámica de los procesos en curso. La relación de los procesos socio espaciales con la producción del espacio merece una nueva importancia en la investigación sobre la metrópoli y su región, porque es en el análisis de las implicaciones de estos procesos que alcanzamos posibles entendimientos sobre las complejidades de la nueva configuración metropolitana. Para el análisis de este problema, elegimos los procesos de concentración y centralización de la dinámica territorial de las actividades urbanas en el área metropolitana, dispersas y fragmentadas, y la lógica de la producción espacial. Este artículo tiene como objetivo comprender las nuevas dimensiones de la lógica de la producción espacial en la metrópoli de Río desde la perspectiva teórica de los conceptos de concentración y centralización del capital y las actividades urbanas. El análisis gravitará hacia la relación entre la dinámica territorial de las actividades que hacen que la producción espacial sea más dinámica y sus implicaciones para el proceso de reestructuración metropolitana. Con este fin, examinaremos algunas hipótesis y consideraciones presentadas por investigadores que han abordado el problema de estos procesos en áreas metropolitanas para contribuir a la comprensión de las complejidades de las metrópolis contemporáneas y sus nuevas características anunciadas a través de estos procesos en curso y colocadas aquí en nuestra lupa. Palabras clave: Concentración, centralización, actividades urbanas, producción espacial, Metrópolis Rio 


\begin{abstract}
The last quarter of the twentieth century and the almost two decades of the twenty-first century comprise the timeframe in which it is possible to see very clearly the intense socio-spatial transformations that the metropolitan spaces have been going through given the intensification of the dynamics of the ongoing processes. The relationship of socio-spatial processes with the production of space deserves new prominence in research on the metropolis and its region, because it is in the analysis of the implications of these processes that we reach possible understandings about the complexities of the new metropolitan configuration. For the analysis of this problem, we chose the processes of concentration and centralization of the territorial dynamics of urban activities in the metropolitan area - dispersed and fragmented - and the logic of space production. This paper aims to understand the new dimensions of the logic of space production in the Rio Metropolis from the theoretical perspective of the concepts of concentration and centralization of capital and urban activities. The analysis will gravitate to the relationship between the territorial dynamics of the activities that make space production more dynamic and their implications for the process of metropolitan restructuring. To this end, we will examine some hypotheses and considerations presented by researchers who have been addressing the problem of these processes in metropolitan areas to contribute to the understanding of the complexities of contemporary metropolises and their new features announced through these ongoing processes and placed here in our magnifier.
\end{abstract}

Keywords: Concentration, centralization, urban activities, space production, Rio Metropolis.

\title{
Résumé
}

Le dernier quart du vingtième siècle et les presque vingt ans du vingt et unième siècle constituent la période au cours de laquelle il est possible de voir très clairement les transformations socio-spatiales intenses subies par les espaces métropolitains compte tenu de l'intensification de la dynamique des processus en cours. La relation entre les processus socio-spatiaux et la production de l'espace mérite une nouvelle place dans la recherche sur la métropole et sa région, car c'est dans l'analyse des implications de ces processus que nous parvenons à une compréhension possible de la complexité de la nouvelle configuration métropolitaine. Pour l'analyse de ce problème, nous avons choisi les processus de concentration et de centralisation de la dynamique territoriale des activités urbaines dans la région métropolitaine - dispersés et fragmentés - et la logique de la production spatiale. Cet article vise à comprendre les nouvelles dimensions de la logique de la production spatiale dans la métropole de Rio à partir de la perspective théorique des concepts de concentration et de centralisation du capital et des activités urbaines. L'analyse portera sur la relation entre la dynamique territoriale des activités qui rendent la production de l'espace plus dynamique et ses implications pour le processus de restructuration métropolitaine. À cette fin, nous examinerons certaines hypothèses et considérations présentées par des chercheurs qui se sont penchés sur le problème de ces processus dans les régions métropolitaines afin de contribuer à la compréhension des complexités des métropoles contemporaines et de leurs nouvelles fonctionnalités annoncées par ces processus en cours et placées ici dans notre loupe.

Mots-clés : Concentration, centralisation, activités urbaines, production spatiale, Métropole Rio. 


\section{Introdução}

Inspirados, especialmente, nas análises, hipóteses e contribuições interpretativas da reestruturação urbano-industrial de São Paulo e do Rio de Janeiro, buscamos nos trabalhos de Sandra Lencioni (1994, 2008, 2014) e Fany Davidovich (1999, 2001) estabelecer um paralelo entre a tendência e o fato novo na compreensão da produção do espaço metropolitano. As abordagens interpretativas propostas por essas autoras sobre os processos espaciais em curso nas duas maiores metrópoles do Brasil, São Paulo e Rio de Janeiro, bem como as contribuições teóricas acerca dos conceitos de concentração e centralização, alinham nossa proposta para este trabalho, que é compreender as novas dimensões da lógica de produção do espaço das metrópoles, especialmente a Metrópole Fluminense.

Tanto Lencioni, quanto Davidovich são categóricas ao afirmarem que as transformações que configuram atualmente as novas diretrizes do urbano e das grandes aglomerações metropolitanas precisam ser analisadas com vista à uma compreensão maior da escala e dos níveis dos processos espaciais em curso. Segundo essas autoras trata-se do debate a respeito da produção contemporânea do espaço (DAVIDOVICH, 2001; p. 326) e que converge para destacar algumas das características da metrópole que se metamorfoseia nesse contexto trazendo a tona a importância da apreensão de processos espaciais tais como o de concentração e de centralização (LENCIONI, 2008; p. 16) sob a égide do fortalecimento da territorialidade do capitalismo financeiro nos espaços da metrópole contemporânea.

A relação estabelecida entre a dinâmica territorial de concentração das atividades econômicas nos espaços metropolizados e a centralização de comando, gestão e fluxos materiais e imateriais fortemente exercidas pelas metrópoles, permite-nos uma visão mais atenta também para o processo de reestruturação do espaço do Rio de Janeiro com a constante expansão de suas centralidades e limites para os eixos de dispersão metropolitana.

Na primeira parte deste trabalho faremos uma breve abordagem histórica do desenvolvimento das atividades urbanas na cidade do Rio de Janeiro com o intuito de aguçar a problemática dos conceitos de concentração e centralização. Destacaremos a tendência e o fato novo na perspectiva da compreensão da produção do espaço e a configuração contemporânea desta porção do espaço urbano brasileiro ainda mais central no debate da atual fase do capitalismo e dos rumos da urbanização. Sendo a tendência a histórica concentração das atividades urbanas na cidade do Rio e com isso o desenvolvimento de centralidades que contribuíram para torná-la uma das maiores metrópoles do Brasil. O fato novo repousa na análise de como essas centralidades se reforçam através de uma nova configuração espacial dessas metrópoles, tendo as funções globais e a intensificação das integrações regionais os principais elementos de compreensão da produção contemporânea do espaço.

Na segunda parte, teceremos considerações sobre como a dinâmica territorial de dispersão das atividades urbanas ao longo dos eixos da Metrópole Rio e o processo de acumulação de capital e produção de riquezas concentradas nessa porção do espaço contribuem para a compreensão atual dos processos espaciais de concentração e centralização. Discutiremos a reafirmação da centralidade da Metrópole Rio na nova fase da urbanização e as implicações de uma reestruturação do espaço no seu em torno que recoloca as periferias metropolitanas no debate acerca dos processos de produção do espaço contemporâneo. 


\section{Rio metropolitano: concentração e centralização, dispersão e fragmentação}

As últimas décadas do século $\mathrm{XX}$ e os primeiros anos do século XXI compreendem o intervalo de tempo no qual é possível perceber intensas transformações espaciais pelas quais os espaços metropolitanos vêm passando dada a intensificação das dinâmicas dos processos em curso. A relação dos vários processos espaciais com o da produção do espaço merece novo destaque nas pesquisas sobre a metrópole e sua região, pois é na análise das implicações desses processos que alcançamos possíveis compreensões sobre as complexidades da nova configuração metropolitana. Elegemos para a análise desta problemática os processos de concentração e centralização da dinâmica territorial das atividades urbanas na área metropolitana fluminense - sob o pressuposto da dispersão e fragmentação de sua conformação espacial.

As novas dimensões da lógica de produção do espaço metropolitano inserem-se na relação entre a dinâmica territorial das atividades urbanas e a centralização de comando, gestão e fluxos (materiais e imateriais) e as implicações dessa relação na reestruturação do espaço. A partir dessa relação poderemos colaborar para a compreensão do processo de reestruturação do espaço manifesto pela reprodução do fato urbano de caráter metropolitano. Para tanto, examinaremos algumas hipóteses e considerações apresentadas por autores que vêm debruçando-se sobre a problemática desses processos em áreas metropolitanas a fim de contribuir para o entendimento das complexidades da Metrópole Rio ${ }^{1}$ e sua região.

Inspirados, especialmente, nas análises, hipóteses e contribuições interpretativas de Lencioni, ao analisar a dinâmica metropolitana de São Paulo, e Davidovich, a do Rio de Janeiro, vimos que as transformações que configuram atualmente as novas diretrizes do urbano e das grandes aglomerações metropolitanas precisam ser analisadas com vista à uma compreensão da complexidade relacional dos processos espaciais em curso. Segundo essas autoras trata-se do debate a respeito da produção contemporânea do espaço (DAVIDOVICH, 2001, p. 326) e que converge para destacar algumas das características da metrópole que se metamorfoseia nesse contexto trazendo à tona a importância da apreensão de processos espaciais tais como o de concentração e de centralização (LENCIONI, 2008, p. 16) sob a égide do fortalecimento da territorialidade do capitalismo financeiro nos espaços da metrópole contemporânea, inaugurando um novo ciclo de reestruturação e subordinando as continuidades do processo civilizatório na dimensão do fenômeno urbano. A relação estabelecida entre a dinâmica territorial de concentração das atividades urbanas e a centralização de comando, gestão e fluxos (materiais e imateriais) na Metrópole Rio permite-nos uma visão mais atenta para o processo de reestruturação do espaço fluminense.

Previamente destacamos a tendência e o fato novo na perspectiva da compreensão da produção do espaço metropolitano e sua conformação na urbanização contemporânea. Sendo a tendência a histórica concentração das atividades urbanas na cidade do Rio de Janeiro e com isso o fortalecimento de sua centralidade. O novo repousa no fato de que com a reprodução da metrópole em direção aos eixos principais de sua aglomeração metropolitana, novas centralidades se reforçam através de uma configuração espacial intensificada por integrações regionais cada vez mais determinantes para a reprodução do capital e da manutenção de sua lógica perversa flagrante no processo de produção do espaço e da vida - esse aspecto, especialmente, retornaremos mais adiante.

A reafirmação da centralidade da Cidade do Rio de Janeiro na fase da urbanização contemporânea não aniquila as centralidades em sua área de influência e na periferia metropolitana, contudo, amplia as fossas da fragmentação entre os territórios urbanos da 
aglomeração, não os desintegrando, ao contrário, fortalecendo uma dinâmica de homogeneização periférica e de hierarquização dominante.

Uma breve introdução à geografia histórica do Rio de Janeiro nos possibilita fornecer um panorama à problemática atual. Para Freitag a cidade do Rio de Janeiro era uma "cidade de itinerâncias urbanas". Segundo a autora, tornou-se a primeira referência de metrópole, ainda no período colonial, passando a "sediar o imaginário da cultura europeia e portuguesa" (FREITAG, 2009, p. 30). Nessa época, do início até meados do século XIX, especialmente com a transferência da Família Real e a Corte Portuguesa para o Rio de Janeiro e todos os privilégios e impasses que essa transferência poderia trazer, a Cidade do Rio de Janeiro extravasa em suas funções política, cultural, portuária, comercial. O Rio de Janeiro foi sede de todas as formas de poder instituídas desde 1763, ainda no período Colonial, até a ascensão de Juscelino Kubitschek ao poder, governo no qual se deu a transferência da capital federal do Rio de Janeiro para Brasília, em 1960.

De Capital Federal (1763-1960) à Estado da Guanabara (1960-1974) à Capital do Estado do Rio de Janeiro (1975 até o presente). Todas as funções citadas acima contribuíram para a efervescência do urbano no Rio de Janeiro desde o início do século XIX. O Rio de Janeiro teve sua evolução urbana alavancada por circunstâncias históricas e o desenvolvimento de suas funções proporcionado pela intensidade dos fenômenos políticos, econômicos e socioculturais responsáveis pela dinamização do seu território e pela autonomização da cidade - este último com reflexo negativo na integração territorial com o Estado do Rio de Janeiro após a transferência da capital para Brasília e a fusão entre os Estados da Guanabara e do Rio de Janeiro (DAVIDOVICH, 1999, p. 13).

A transferência da Família Real e da Corte Portuguesa para o Rio de Janeiro, conforme já citamos, trouxe implicações na organização e no desenvolvimento urbano da cidade, especialmente porque se instala no Rio o centro de gravidade do poder da Colônia e da Metrópole. É a partir do final do século XIX e as primeiras décadas do XX que as transformações na Cidade do Rio de Janeiro e na sua aglomeração imediata e intermediária ganham efeitos estruturantes para uma conformação espacial urbanoregional (ABREU, 2008; VIANA, 2013, 2018).

O Rio de Janeiro seguia como centro de poder e de riqueza, desenvolvendo para além de sua função político-administrativa, a centralização dos negócios e exportação do café, introduzidos em terras do Vale do Paraíba (leito do principal eixo rodoviário entre Rio-São Paulo). A expansão da cafeicultura e o movimento comercial desenvolveu, a partir do principal elemento estruturante da urbanização paulista, a ferrovia, uma rede de cidades que impulsionou as mais profundas transformações território de São Paulo. Esse conjunto de transformações proporcionou à economia urbana de São Paulo um fortalecimento que não ocorreu no Rio de Janeiro, onde a manutenção do trabalho escravo nas lavouras não oportunizou o mesmo efeito que em São Paulo com a mão de obra do imigrante (MONBEIG, 2004; MARTINS, 2010). Já na década de 1920, o Rio de Janeiro começa a perder importância em relação a São Paulo que, com o status de "locomotiva do Brasil", torna-se o centro dos negócios do café, da indústria e dos serviços financeiros, respectivamente.

Apesar da perda de importância no cenário nacional já a partir dos anos 1920 (NATAL, 2003, p. 427) o Rio de Janeiro estabelece com São Paulo um eixo dinamizador a partir do qual o processo de urbanização passa a agregar uma série de novas funções urbanas, novas formas e uma estrutura regional complexa, provenientes da contínua herança histórica de concentração das atividades urbanas por aquela cidade e do sucesso da cafeicultura por essa ${ }^{2}$.

Nesse sentido apresenta-se a tendência a qual nos referíamos anteriormente: a cidade do Rio de Janeiro possui aspectos históricos que a evidenciam em detrimento de 
outras cidades e metrópoles brasileiras e de sua própria aglomeração metropolitana, por nela gravitar a concentração e a centralização das atividades urbanas há mais de dois séculos. As funções que exerceu no passado a colocaram em conexão com o externo, com o de fora, devido as suas atividades político-administrativas e comerciais e nessa atual fase da urbanização metropolitana, continua a exercer conexão com o de fora, agora em uma perspectiva da globalização da economia e do capitalismo financeiro, pondo-se o desafio, também histórico, dos limites do crescimento econômico fluminense sustentado na sua metrópole e da pouca densidade produtiva de sua região (SOBRAL, 2015a; 2015b).

A explosão do fenômeno urbano na forma de regiões metropolitanas a partir da década de 1970. As inúmeras teorias sobre sua configuração, planejamento e criação de políticas públicas de interesse comum aos municípios integrantes a tais regiões instituídas marcaram os debates e ocuparam as pautas de pesquisadores e políticos. O futuro se anunciava e atendia pelo nome de metrópole. Passados pouco mais de 40 anos do marco institucional que oficializou os primeiras e mais consolidadas regiões metropolitanas do Brasil, seguidos da renovação dos debates e estudos urbanos para que se compreendesse melhor essa configuração espacial que era em si a superação da própria cidade. A metrópole parecia ser o ponto máximo da forma urbana. A cidade implodiu. A metrópole explodiu.

A urbanização mostrou-se um processo tão complexo, capaz de atingir fases pouco cogitadas: da vila à cidade, da cidade à metrópole, da metrópole à cidade-região (LENCIONI, 2006; BERNARDES e SOARES, 1990; SCOTT et al. 2001). Na fase atual o marco espaço-temporal não é mais a cidade e sua função política e administrativa, mas a metrópole policêntrica e dispersa. Estamos diante da metropolização do espaço. Da difusão da metrópole e ao mesmo tempo da reafirmação de sua centralidade.

O fato novo, que compreende essa fase atual da urbanização da qual desfrutam intensamente (mas não exclusivamente) a Cidade do Rio de Janeiro e sua aglomeração metropolitana, refere-se a reestruturação da tradicional área metropolitana do Rio de Janeiro, que representa territorialmente a expressão da região urbana fundida na linearidade do eixo centro-periferia. Tanto a configuração territorial quanto a interação dos processos globais de reprodução do atual momento do capitalismo, refazem-se sob as heranças dos processos históricos de evolução urbana e desenvolvimento das atividades econômicas no contexto da urbanização e da industrialização ao longo do século XX, subordinando formas e funções arcaicas, mas sem as superar.

Todavia uma coisa ambas as formas urbanas (antiga e nova) têm em comum, tanto a cidade política ou industrial quanto a metrópole contemporânea são ordem, ordenação e poder. Diante de um mais alto patamar do processo de urbanização, a metrópole supera a cidade e supera a si mesma quando ao se manter centro permite a criação de novos centros, ou quando ao se tornar dispersa regula a produção e a valorização dos capitais envolvidos na produção, centralizando o comando e a gestão dos fluxos materiais e imateriais envolvidos nessa produção - incluindo a produção do próprio espaço.

Verdadeiramente assistimos à conformação de um fato novo, marcado pelo fortalecimento de tendências que intensificam os processos espaciais de concentração e centralização das atividades urbanas e do capital na Metrópole Rio em detrimento de sua aglomeração metropolitana. Isso porque, os processos de concentração e centralização renovaram a função de comando, gestão e controle da Metrópole Rio. Especialmente porque sob a função da metrópole contemporânea repousa a racionalidade da acumulação capitalista, diante da qual o caráter social dos produtos só se manifesta a posteriori, nas trocas comerciais, pois as forças produtivas estão dispersas e os processos de produção 
não estão coordenados (AGLIETTA, 1986, p. 192). Entretanto, essa integração se dá na concentração e na centralização do capital e do trabalho, pois

\begin{abstract}
"la concentración es la ampliación de la propriedad dentro de un proceso de valorización" e "la centralizacíon del capital reagrupa bajo un mismo poder de disposición y de control ciclos de valorización que pueden permanecer separados entre sí desde el punto de vista de la producción y realización de las mercancías" (Ibidem, p. 193).
\end{abstract}

A concentração permite a ampliação da acumulação e a centralização garante uma alternativa a concorrência, mantendo, por vezes, o produto, mas associando diferentes capitais, ampliando o poder de decisão, gestão e comando. Em Michael Aglietta encontramos que

\begin{abstract}
con la centralización de la economía, tal desaparecen innumerables capitales individuales por absorción, mientras que otros son reagrupados por fusión o consolidación. La centralización del capital es, pues, una forma violenta de la competencia. [...]. Pero la centralización del capital tiene un significado más general. Es un efecto del proceso general de desvalorización del capital sobre el fraccionamiento de los capitales; mediante el cual el movimento de la acumulación global encuantra nuevas condiciones para su futuro desarrollo. Por eso la centralización del capital no se limita a determinados campos. [...] las fusiones entre capitales se producen por oleadas en íntima relación con el movimento global de la formación de capital. (AGLIETTA, 1986, p. 195 e 196).
\end{abstract}

A desconcentração territorial das indústrias fluminenses (ou mesmo o movimento de desindustrialização-reindustrialização) da área metropolitana em direção as áreas de dispersão da atividade produtiva não contradizem o circuito de concentração e centralização do capital na Metrópole Rio. Isso por dois motivos específicos: primeiramente, por considerarmos o que foi colocado por Aglietta no que se refere ao movimento de acumulação global, que flexibiliza a produção e o trabalho, mas regula a concorrência e garante a centralização do capital. Em segundo, porque permite que, com a dinamização da economia global através dos serviços de inteligência computacional e a ampliação do aporte tecnológico de distribuição de informação e comando, a direção das forças produtivas possam se alargar para além do seu centro gestor sem qualquer prejuízo a produtividade.

É importante considerar a observação feita por Davidovich em relação ao estado do Rio de Janeiro, afirmando que "as indústrias [...] e outras atividades, que compõem a configuração espacial daquele território, tem sede ou representação principal na cidade do Rio de Janeiro" (DAVIDOVICH, 2001a, p. 328). É o caso, por exemplo, da localização da Associação Brasileira das Empresas de Serviços de Petróleo (ABESPetro), que congrega 51 empresas do ramo, grande parte de capital estrangeiro, com sede na área central da metrópole fluminense.

Isso reforça o que vimos apresentando até aqui. O desenvolvimento das economias de aglomeração e a dispersão das atividades produtivas ao longo dos eixos de circulação do território fluminense tenderam a estreitar a dependência dessas economias em relação à Metrópole Rio em um processo de concentração e centralização do capital. A dispersão das unidades produtivas pelo território não comprometeu a centralidade da metrópole fluminense. Como aponta Lencioni "este espraiamento das atividades foi historicamente proporcionado pela tecnologia, principalmente por aquelas capazes de processar e explorar informações, permitindo unir a descontinuidade espacial do processo de produção" (LENCIONI, 1994, p. 59). 
No caso específico da Metrópole Rio, o setor de serviços tem uma particular importância pois uma das maiores demandas do mercado e da economia global no que diz respeito ao aparelhamento e suporte à produção se revela pelo setor de serviços, especialmente o de transporte e de telecomunicação. A participação percentual acumulada da metrópole do Rio de Janeiro é de 19,02\% (tabela 1).

Tabela 1 - Rio de Janeiro: Posição ocupada pelos maiores municípios*, em relação ao valor adicionado bruto dos Serviços e participações percentuais relativa e acumulada (2011)

\begin{tabular}{|c|c|c|c|c|c|}
\hline \multirow{2}{*}{ Municípios } & \multicolumn{2}{|c|}{ Posição ocupada } & \multirow{2}{*}{$\begin{array}{c}\text { Valor adicionado } \\
\text { bruto dos serviços } \\
(1000 \mathrm{R} \$)\end{array}$} & \multicolumn{2}{|c|}{ Participação percentual (\%) } \\
\hline & Brasil & RJ & & Relativa & Acumulada \\
\hline Rio de Janeiro & $2^{\circ}$ & $1^{\circ}$ & 140138244 & 5,92 & 19,02 \\
\hline Duque de Caxias & $8^{\circ}$ & $2^{\circ}$ & 15805674 & 0,67 & 39,60 \\
\hline Niterói & $16^{\circ}$ & $3^{\circ}$ & 9918503 & 0,42 & 45,38 \\
\hline São Gonçalo & $21^{\circ}$ & $4^{\circ}$ & 9144500 & 0,39 & 47,38 \\
\hline
\end{tabular}

* São Paulo é o município brasileiro com o maior valor adicionado bruto dos serviços, aproximadamente R 3,1 bilhões, e participações percentuais relativa e absoluta de $13,09 \%$.

Fonte: IBGE, 2011

Elaboração: Juliana Luquez.

A cidade do Rio de Janeiro tem nesse índice um dos elementos de fortalecimento de sua centralidade e de sua função como centro de comando e gestão, especialmente a partir dos serviços modernos de logística e informação. Como destaca Davidovich "Rio de Janeiro e São Paulo [...] estariam deixando de ser a sede da produção propriamente dita, como sucedeu no auge do processo urbano-industrial, para se posicionarem como centros de controle e gestão e polos de serviços avançados, que atendem aos interesses da grande empresa" (DAVIDOVICH, 1999, p. 6). A autora observa também que

No espaço de extensão da metrópole, o espaço da metropolização, mudanças tem lugar em cidades que buscam aparelhar-se para enfrentar tempos de competitividade crescente, envolvendo, medidas de produtividade e de superação de déficits. Sobressaem aquelas que dispõem de melhor infraestrutura e recursos técnicos, inclusive automação, aquelas onde foram adotados contratos flexíveis de trabalho e normas de controle ambiental, constituídas, aliás, em requisito para aprovação de financiamentos concedidos pelo BNDES. Ou seja, são cidades que se capacitam para diminuir custos de produção. Poderiam, hoje, ser definidas, não só como pontos de apoio da metrópole, das empresas nela sediadas, mas como nós de articulação de um contexto que tem em mira a economia da globalização. [...]. No espaço da metropolização de São Paulo, que se estruturou com uma densa rede de estradas, de comunicações e de cidades o suposto é que essa matriz se distribui, de algum modo, entre centros do porte de Campinas, São José dos Campos, Santos ou Sorocaba. Já, no caso do Rio de Janeiro, a matriz tem concentração na metrópole, ou melhor, na cidade central, onde se processam, inclusive, os principais acertos e negociações em torno de projetos e empreendimentos; assim, é na cidade do Rio de Janeiro que se reúnem personagens que tratam da instalação da Peugeot - Citroën no Estado do Rio, desde representantes da empresa e da prefeitura de Porto Real, aos da Telerj, da Embratel, da Rio-Gás e do Porto de Sepetiba, prestadores de serviços de infraestrutura que vão participar do projeto, e ainda os que se referem ao setor financeiro, como o BNDES, o Banco Interatlântico, o Codin e outros. (DAVIDOVICH, 1999, p. $5)$.

Davidovich ressalta a singularidade histórica do processo de estruturação da Metrópole Rio, sua relação com a conformação de sua região metropolitana e o interior do estado fluminense. A concentração de atividades, pessoas, renda, trabalho e tecnologia na capital fluminense agravou a fragmentação territorial e "traduz a contradição entre a 
posição urbana sucessivamente acumulada pela cidade do Rio de Janeiro e o isolamento secular mantido em relação à sua interlândia imediata" (DAVIDOVICH, 2001b, p. 69).

Ainda sobre esse aspecto, o economista Sobral, acrescenta que 1) a fragilidade institucional do estado do Rio de Janeiro em planejar uma política metropolitana, 2) a fraca densidade produtiva da periferia metropolitana e 3) o dinamismo econômico apoiado, principalmente, nas atividades de serviços, que vêm se apresentando incapazes de incorporar mão de obra e gerar renda crescente, são os fatores que reforçam os impasses da dinâmica territorial fluminense e a centralização de comando, gestão e fluxos na Metrópole Rio (SOBRAL, 2015a). A "crise" se reforça mesmo diante do ciclo recente de grandes investimentos públicos e privados característicos da atual fase de reestruturação do espaço metropolitano do Rio de Janeiro, quais sejam:

- Complexo Siderúrgico do Atlântico (Rio de Janeiro e Itaguaí);

- Complexo Petroquímico do Rio de Janeiro (Itaboraí e São Gonçalo);

- Implantação do Arco Metropolitano do Rio de Janeiro (Itaboraí, Magé, Guapimirim, Duque de Caxias, Nova Iguaçu, Queimados, Japeri, Seropédica e Itaguaí);

- Programa de Modernização e Expansão da Frota (PROMEF), com encomendas de navios petroleiros aos estaleiros da Baía de Guanabara (Rio de Janeiro, Niterói e São Gonçalo)

$\mathrm{Na}$ atual fase da urbanização, gerida pelas determinações contraditórias do capitalismo financeiro, o protagonismo da cidade do Rio mediante as demandas da economia global tem sido um dos desafios para o desenvolvimento das cidades metropolitanas e do entorno da região metropolitana do Rio. Neste sentido, Davidovich sinaliza alterações recentes na estruturação da Região Metropolitana do Rio de Janeiro (RMRJ). Sua tese aponta para uma reestruturação setorizada do espaço. A saber:

Quadro 1 - RMRJ: reestruturação setorizada do espaço (2018)

\begin{tabular}{|c|l|}
\hline $\begin{array}{c}\text { Primeiro setor de } \\
\text { reestruturação da RMRJ }\end{array}$ & $\begin{array}{l}\text { Refere-se à cidade do Rio de Janeiro e sua esmagadora concentração de } \\
\text { empreendimentos e iniciativas de reestruturação socioespacial. } \\
\text { Destacando-se, sem precedentes, a Zona Leste na Cidade, especialmente os } \\
\text { bairros da Barra da Tijuca, Jacarepaguá e Campo Grande. }\end{array}$ \\
\hline $\begin{array}{c}\text { Segundo setor de } \\
\text { reestruturação da RMRJ }\end{array}$ & $\begin{array}{l}\text { Refere-se ao eixo comandado por Niterói, na porção oriental da Baía de } \\
\text { Guanabara, destacando-se ainda os municípios metropolitanos de São } \\
\text { Gonçalo, Itaboraí e Maricá. }\end{array}$ \\
\hline \multirow{2}{*}{$\begin{array}{c}\text { Terceiro setor de } \\
\text { reestruturação da RMRJ }\end{array}$} & $\begin{array}{l}\text { Refere-se a Região da Baixada Fluminense, onde os eixos de comunicação } \\
\text { território metropolitano com a metrópole fluminense. Neste setor estão } \\
\text { incluídos os municípios de Belford Roxo, Duque de Caxias, Guapimirim, } \\
\text { Itaguaí, Japeri, Magé, Mesquita, Nilópolis, Nova Iguaçu, Paracambi, } \\
\text { Queimados, São João de Meriti e Seropédica. }\end{array}$ \\
\hline
\end{tabular}

Elaboração: Juliana Luquez, a partir de Davidovich, 1999.

É importante ressaltar que este contexto de reestruturação tem produzido novos nexos de integração no território fluminense, ou seja, da Região Metropolitana com o seu entorno no interior do estado. Esta é uma consideração importante, pois vai ao encontro de todos as considerações que tecemos até aqui, especialmente no alinhamento da perspectiva interpretativa de compreensão da produção contemporânea do espaço a partir da dinâmica de reestruturação, pela qual o processo de metropolização inaugura os eixos de dispersão, ampliando as relações de reprodução do capital na realização da urbanização e fortalecendo os laços (real e virtual) com a globalização. 
O mapa 1 apresenta a aglomeração metropolitana do Rio de Janeiro considerando o território institucionalizado de sua Região Metropolitana, conforme atualização em 2013. Composta por 21 municípios, sendo eles: Rio de Janeiro, Belford Roxo, Cachoeiras de Macacu, Duque de Caxias, Guapimirim, Itaboraí, Itaguaí, Japeri, Magé, Maricá, Mesquita, Nilópolis, Niterói, Nova Iguaçu, Paracambi, Queimados, Rio Bonito, São Gonçalo, São João de Meriti, Seropédica e Tanguá. A maior parte da população fluminense concentra-se na Região Metropolitana do Rio de Janeiro, sendo a população total do Estado do Rio 16.369.178, sua população metropolitana é de 12.064.084, o que equivale a $73,7 \%$ de sua população total. Além da Metrópole Rio, com 6.422.922 habitantes, o destaque está para os municípios de São Gonçalo (1.025.507 habitantes), Duque de Caxias (873.921 habitantes), Nova Iguaçu (804.815 habitantes) e Niterói (494.200 habitantes) $)^{3}$.

Mapa 1 - Região Metropolitana do Rio de Janeiro: aglomeração e mancha urbanas (2018)

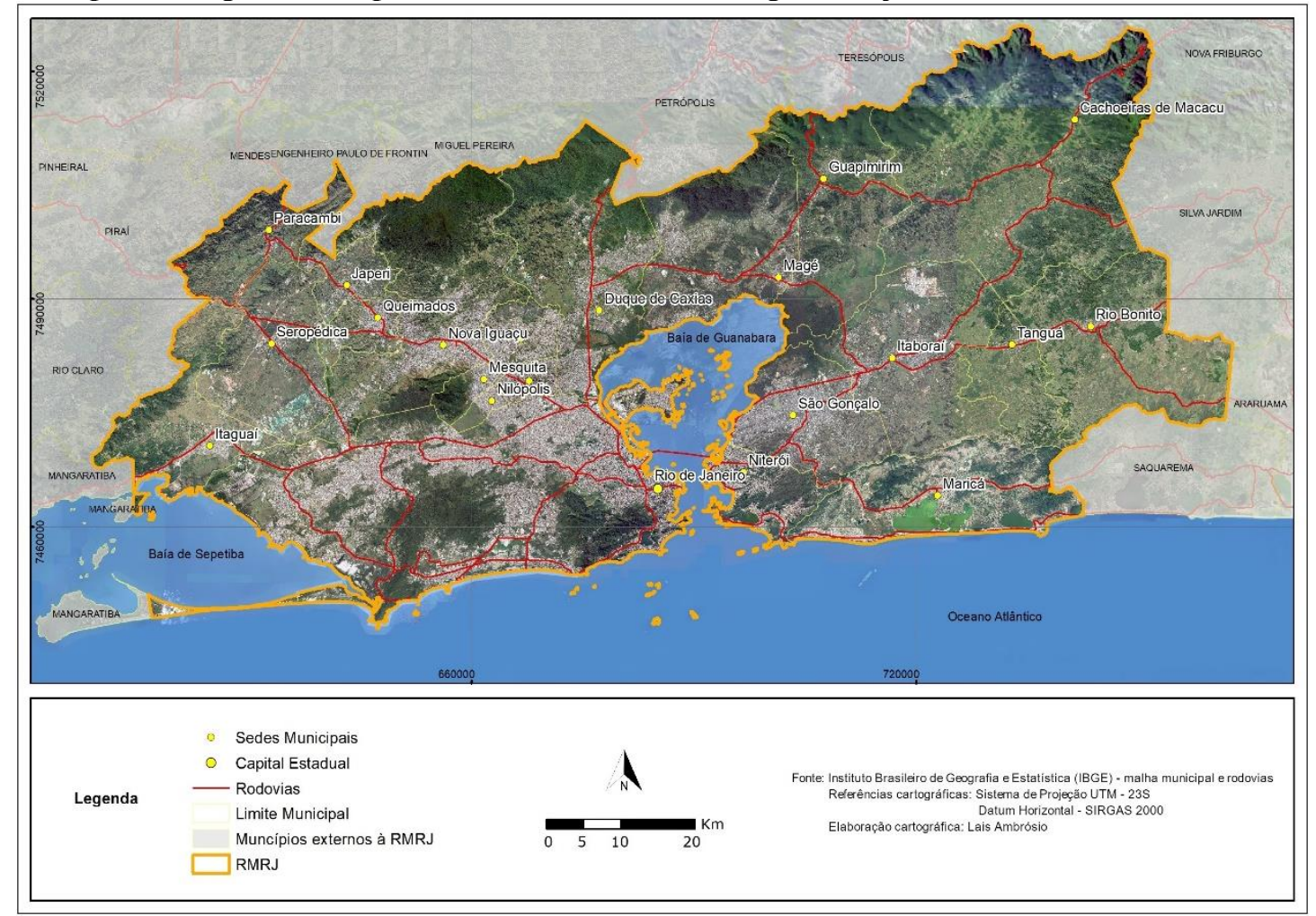

A concentração populacional nesses municípios tem sua razão no processo de industrialização do território fluminense e na consequente transformação do espaço das cidades entre as décadas de 1930 a 1980 consolidando a urbanização no em torno da Baía de Guanabara e expandindo os eixos de dispersão metropolitana para os demais municípios resultando na conurbação das áreas ocupadas na orla ocidental e oriental da Baía de Guanabara (GEIGER, 1956).

Vemos na aglomeração metropolitana do Rio de Janeiro uma conformação a partir de eixos radiais, inicialmente consolidados na faixa litorânea da orla ocidental da Baía de Guanabara, expandindo a urbanização para os subúrbios contínuos e descontínuos da cidade do Rio de Janeiro, entre os maciços da Tijuca, da Pedra Branca e de Gericinó e a porção leste da Guanabara. A orla oriental da Baía de Guanabara, o maior eixo descontínuo da urbanização fluminense, teve sua consolidação urbana na forma de conurbação entre os territórios de Niterói e São Gonçalo. A industrialização nessa região 
construiu para si a urbanização que precisava, caracterizada pela instalação de uma forte infraestrutura portuária, ferroviária e bondes, vilas operárias, parques industriais, comércio, escolas operárias, cinemas, etc.

Mendes destaca em seu trabalho a estreita relação que se estabeleceu entre os municípios de São Gonçalo e Niterói. Devido à expansão urbana proporcionada pela conurbação de alguns bairros operários, especialmente, Neves (São Gonçalo) e Barreto (Niterói), o autor as descreve como "cidades gêmeas" e acrescenta que a vida urbana que se desenvolveu em Niterói também se desenvolveu em São Gonçalo mediada pelo processo de industrialização do território fluminense (MENDES, 1950).

A conurbação verificada na aglomeração metropolitana do Rio de Janeiro como forma espacial da reprodução da Metrópole Rio policêntrica, ressalta a dominação de "superposições e justaposições de espaços com tendências à conformação de territórios demarcados que resultam das inclusões produtivas no processo social" (SEABRA, 2003, p. 9). Ora, se considerarmos o urbano como o processo social em curso e em vias de realização, as inclusões produtivas referem-se as centralidades da totalidade da realidade urbana fluminense que passam a compor o espaço das contradições no movimento da reprodução da metrópole. Em outras palavras, vemos erigir na complexidade metropolitana a relação entre dispersão e fragmentação, reforçando a concentração e a centralização da Metrópole Rio; todos esses processos característicos da metropolização ${ }^{4}$ do espaço fluminense.

\section{A dispersão metropolitana na lógica da produção contemporânea do espaço sob os processos de concentração das atividades econômicas e centralização do capital}

O caráter difuso da aglomeração metropolitana do Rio de Janeiro verifica-se a partir da identificação dos eixos de conformação e expansão da urbanização no em torno da Baía de Guanabara (mapa 2). Identificamos 6 (seis) eixos de dispersão e espraiamento da urbanização. Os eixos $\mathrm{A}_{1}, \mathrm{~B}_{1}, \mathrm{C}$ e D constituem os territórios de inclusão produtiva do primeiro momento da urbanização fluminense, aqui chamado de urbano-industrial. Os eixos $\mathrm{A}_{2}, \mathrm{~B}_{2}$, E e $\mathrm{F}$ constituem os territórios de inclusão produtiva do segundo momento da urbanização fluminense, aqui denominado metropolitano-financeiro.

No que se refere ao momento urbano-industrial a urbanização apresenta-se como determinação histórica na constituição da sociedade moderna, este processo corresponde a consolidação do modelo de acumulação capitalista sob as condições gerais de produção da industrialização. A ruptura nas determinações históricas do movimento de urbanização, no qual irrompe o momento metropolitano-financeiro, inaugurando a sociedade pós-industrial ou sociedade urbana, no qual

\footnotetext{
A metrópole se coloca ao mesmo tempo como uma condição para a reprodução do capital, um meio utilizado para a sua reprodução e, ainda, um produto do próprio capital. Isso, num quadro de profundas alterações na dinâmica do capital imobiliário e financeiro, como estratégias de renovação da reprodução capitalista (LENCIONI, 2011, p. 136).
}

O caminho da problematização da realidade urbana fluminense, proposto aqui pelas vias da compreensão do movimento de produção e reprodução da metrópole, encontra nas premissas acima o direcionamento para a identificação dos eixos de conformação e expansão da urbanização da Região Metropolitana do Rio de Janeiro bem como os nexos desses processos com o da reestruturação do espaço - este último, defendido aqui, como álibi da reprodução do capital no momento recente. 


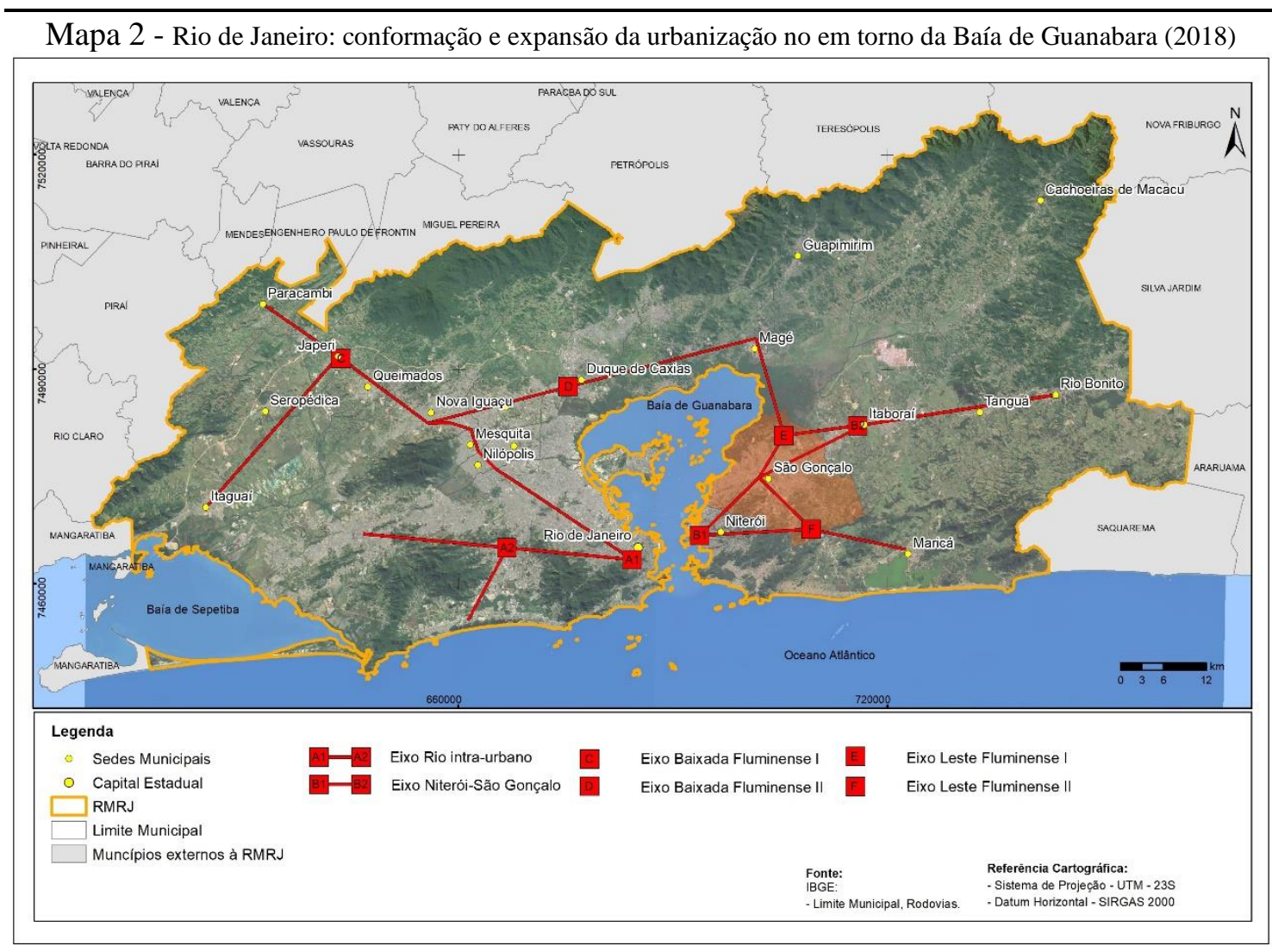

Os eixos $\mathrm{A}_{1}, \mathrm{~B}_{1}, \mathrm{C}$ e $\mathrm{D}$, embora consolidados na inclusão produtiva do processo social de urbanização, ganham novas dinâmicas frente às estratégias de renovação da reprodução capitalista. Os eixos $\mathrm{A}_{2}, \mathrm{~B}_{2}$, E e F compõem as novas territorialidades do fato urbano, tendo o processo de metropolização sua maior síntese complexa.

Os eixos $\mathrm{A}_{1}, \mathrm{~B}_{1}, \mathrm{C}$ e $\mathrm{D}$, consolidados sob a lógica de reprodução urbanoindustrial, conferiram à Metrópole Rio alto grau de concentração e centralização considerando a articulação metrópole-aglomeração e as atividades urbanas. Ao mesmo tempo que as relações de produção reforçaram a concentração e centralização das atividades urbanas historicamente desenvolvidas na cidade do Rio de Janeiro manifestaram a policentralidade característica da metrópole capitalista na forma espacial da periferização, integrando estreitamente os territórios contíguos de Niterói e São Gonçalo, Nova Iguaçu e Duque de Caxias às lógicas e contradições da reprodução da metrópole, transformando tais municipalidades em complexidades urbanas do ponto de vista das relações de produção, propriedade e trabalho.

Aos eixos $\mathrm{A}_{2}, \mathrm{~B}_{2}$, E e $\mathrm{F}$ atribuímos uma dinâmica especulativa, característica do momento metropolitano-financeiro, fundado na negação da cidade e na valorização do urbano sob a forma espacial da segregação, insere à urbanização sua fase mais complexa e ao mesmo tempo reforça suas continuidades históricas. Os refúgios tidos como seguros, sustentáveis e totalmente integrados à Metrópole Rio, distam algumas poucas dezenas de quilômetros do núcleo metropolitano, porém ligam-se apenas por caminhos rodoviários em sua maioria acessível somente por transporte próprio, o cotidiano passa a se reproduzir na imaterialidade dos fluxos (de dinheiro, de informação) e na materialidade da rede de cabos de fibra óptica que torna possível a penetração das atividades urbanas cada vez mais determinantes da vida cotidiana. As municipalidades de Magé, Guapimirim, Itaboraí, Tanguá, Rio Bonito e Maricá são exemplos dessa nova configuração da urbanização fluminense. 
O espaço assume "uma espécie de realidade própria, da mesma maneira que a mercadoria, o dinheiro, o capital, mas de modo distinto"5 (LEFEBVRE, 2000, p. 35). Considerando a hipótese de Henri Lefebvre sobre o espaço como produto social, vamos em busca do modo distinto como o espaço assume essa realidade autônoma no momento histórico de produção capitalista, e produz assim o espaço, o seu espaço de reprodução.

Segundo Marx

\begin{abstract}
Uma coisa pode ser valor de uso sem ser valor. É esse o caso quando sua utilidade para o homem não é medida pelo trabalho. Assim é o ar, a terra virgem, os campos naturais, a madeira bruta etc. Uma coisa pode ser útil e produto do trabalho humano sem ser mercadoria. Quem, por meio de seu produto, satisfaz sua própria necessidade, cria certamente valor de uso, mas não mercadoria. Para produzir mercadoria, ele tem de produzir não apenas valor de uso, mas valor de uso para outrem, valor de uso social. \{E não somete para outrem. O camponês medieval produzia a talha para o senhor feudal, o dízimo para o padre, mas nem por isso a talha ou o dízimo se tornavam mercadoria. Para se tornar mercadoria, é preciso que o produto, por meio da troca, seja transferido a outrem, a quem vai servir como valor de uso.\} Por último, nenhuma coisa pode ser valor sem ser objeto de uso. Se ela é inútil, também o é o trabalho nela contido, não conta como trabalho e não cria, por isso, nenhum valor. (MARX, [1867] 2013, p. 118)
\end{abstract}

O espaço se torna, na fase atual da urbanização contemporânea - a metropolização - o produto com maior valor social agregado e as cidades tornam-se a possibilidade concreta de extração de mais valia e de transferência de valor. Se retornarmos ao mapa 2, veremos que os eixos de conformação e expansão da urbanização fluminense são, em verdade, os eixos de reestruturação do espaço, mas não de todo o espaço e sim de porções do espaço - eis o nexo entre a fragmentação, reestruturação e valorização do espaço. Logo, destacamos a reestruturação do espaço como sendo a possibilidade interpretativa do "modo distinto", ao qual se refere Henri Lefebvre em relação a realidade própria do espaço, ou seja, o caráter reestruturante do valor no processo de produção do espaço.

Se considerarmos que a medida do valor é o trabalho, ou melhor, o tempo de trabalho socialmente necessário à produção, estabeleceremos uma relação lógica: quanto mais trabalho requerido para a produção maior o valor do produto. Contudo é importante atentar-nos, no que se refere ao processo de valorização, às diferentes e sucessivas fases do processo de trabalho (MARX, [1867] 2013, p. 264), como consideradas por Karl Marx, para quem há diferentes processos de trabalho que precisam se realizar para produzir o valor de troca (o produto) e que os elementos constitutivos da produção, mesmo que dispersos no tempo e no espaço, determinam sua valorização. Ora, se o espaço é produto social, sua valorização se dá pelos diferentes processos de trabalho requeridos para a sua produção e, por isso, estruturantes no processo global. Mas não só isso. A relação capitaltrabalho, sob a problemática do espaço, continua o processo de valorização do espaço, formando, transferindo e extraindo do espaço valor produzido em momento anterior. As novas formas de valorização do espaço não põem fim as anteriores, pois essas estão subordinadas àquelas.

Maricato (2015) nos fornece um exemplo da formulação teórica acima apresentada. Para a autora, a urbanização dos baixos salários, característica das cidades da periferia do capitalismo, é marcada pela construção da moradia como forma de produção doméstica e, na maioria das vezes, ilegal, paulatina e durante os horários de folga do trabalho remunerado. Os trabalhadores recebem pouco pela força de trabalho que vendem e nada pela construção de suas próprias moradias, ao contrário, todo o custo é retirado do seu salário. Essa situação, segundo a autora, é um exemplo não só de uma 
produção doméstica no contexto urbano, mas também de produção da cidade, de bairros, de cotidiano.

Essa prática (da autoconstrução das casas) contribuiu para a acumulação capitalista durante todo o período de industrialização no Brasil, particularmente de 1940 a 1980, quando o país cresceu a taxas aproximadas de $7 \%$ ao ano, e o processo de urbanização cresceu $5 \%$ ao ano (IBGE). À industrialização com baixos salários correspondeu a urbanização com baixos salários. O exemplo revela que uma certa modernização e um certo desenvolvimento (industrialização de capital intensivo, produção de bens duráveis) dependeram de um modo pré-moderno, ou mesmo pré-capitalista (a autoconstrução da casa), de produção de uma parte da cidade. Essa imbricação foi (e ainda é) fundamental para o processo de acumulação capitalista nacional e internacional. (MARICATO, 2015, p. 26).

Mesmo os bairros operários, tradicionalmente populares, compostos por casas autoconstruídas não estão fora do processo de valorização, pois o trabalho requerido para a sua produção somado ao trabalho requerido na construção de infraestrutura urbana (vias de comunicação, equipamentos coletivos, comércio e serviços), ao longo do tempo incorporada, faz parte do processo de produção do espaço e da cidade e, portanto, de sua valorização. Se a classe trabalhadora, em um primeiro momento, produz a cidade como valor de uso, as relações sociais envolvidas no processo de produção - quer na fábrica ou na cidade - subordinam a então produção doméstica ao processo de revalorização, pois

Os capitais que ganham com a produção e exploração do espaço urbano agem em função do seu valor de troca. Para eles, a cidade é mercadoria. É um produto resultante de determinadas relações de produção. Se lembrarmos que a terra urbana, ou um pedaço de cidade, constitui sempre uma condição de monopólio - ou seja, não há um trecho ou terreno igual a outro, e sua localização não é reproduzível - estamos diante de uma mercadoria especial que tem um atributo de captar ganhos sob a forma de renda. A cidade é um grande negócio e a renda imobiliária, seu motor central. (MARICATO, 2015, p. 23).

Na aglomeração metropolitana do Rio de Janeiro, as áreas urbanas dos municípios de Nova Iguaçu, Duque de Caxias e São Gonçalo, são exemplos da formulação teórica aqui apresentada. $\mathrm{O}$ espaço urbano construído nessas municipalidades teve como principal agente produtor, por um lado, a classe operária que se consolidou nos anos 1950, se diversificou pós-1960 e se transformou, nas últimas três décadas, em trabalhadores urbanos terciários, terceirizados e informalizados; por outro, os produtores imobiliários, os proprietários fundiários e dos meios de produção e o Estado, articulados, construíram cidades fragmentadas, homogeneizadas e hierarquizadas, cujo caminho da metropolização se faria possível com a concentração das atividades urbanas, a centralização de comando, gestão e fluxos no Metrópole Rio e com a dispersão territorial do fenômeno urbano nas áreas suburbanas e periféricas, para as quais a classe trabalhadora foi sendo assentada e, reproduzindo sua força de trabalho, produziu a regionalização da metrópole fluminense.

Soares (1962), destacou sobre Nova Iguaçu que

Essa grande massa humana, que reside em Nova Iguaçu, se compõe, na sua grande maioria, de uma população pobre que aí foi encontrar habitação de módico aluguel ou então um pequeno lote, de baixo preço, comprado com enorme facilidade de pagamento, para construir sua modesta residência. Nova Iguaçu, como todos os subúrbios do Grande Rio de Janeiro, se caracteriza pelo 
fato de abrigar, predominantemente, uma população pouco favorecida de recursos. (SOARES, 1962, p. 33)

A tabela 2 apresenta Duque de Caxias, Niterói, Nova Iguaçu e São Gonçalo com os maiores números em relação ao pessoal ocupado em atividades industriais na aglomeração metropolitana fluminense, em 1950. À exceção de Niterói, as demais municipalidades destacam-se pelo baixo número de pessoal ocupado no município de residência. $\mathrm{O}$ que nos leva a inferir que o processo de periferização da classe trabalhadora metropolitana fluminense inaugura eixos da Metrópole Rio em direção aos lotes de construções populares que uma vez consolidados agregam valor à terra urbana e dinamizaram o processo de valorização das áreas periféricas e suburbanas da metrópole enquanto realizava a dispersão e a fragmentação do território sob domínio da urbanização industrial.

\begin{tabular}{c|c|c|c|c|c}
\multicolumn{2}{c}{ Tabela 2 - Aglomeração metropolitana fluminense: população e pessoal ocupado no comércio e na indústria (1950) } \\
\hline \multirow{2}{*}{ Município } & População & \multicolumn{2}{c|}{ Pessoal ocupado no comércio } & \multicolumn{2}{c}{ Pessoal ocupado na indústria } \\
\cline { 3 - 6 } & & $\begin{array}{c}\text { Residentes no } \\
\text { município }\end{array}$ & $\begin{array}{c}\text { Ocupados nos } \\
\text { estabelecimentos } \\
\text { do município }\end{array}$ & $\begin{array}{c}\text { Residentes no } \\
\text { município }\end{array}$ & $\begin{array}{c}\text { Ocupados nos } \\
\text { estabelecimentos do } \\
\text { município }\end{array}$ \\
\hline Cachoeiras de Macacu & 16.272 & 199 & 133 & 271 & 82 \\
Duque de Caxias & 92.459 & 2.468 & 1.166 & 11.811 & 3.287 \\
Itaboraí & 19.472 & 331 & 287 & 990 & 643 \\
Magé & 19.735 & 616 & 349 & 5.740 & 4.623 \\
Nilópolis & 46.406 & 1.874 & 625 & 4.749 & 780 \\
Niterói & 186.309 & 8.374 & 5.416 & 14.218 & 14.638 \\
Nova Iguaçu & 74.290 & 3.696 & 1.330 & 13.808 & 3.216 \\
São Gonçalo & 127.276 & 3.806 & 1.531 & 13.263 & 6.612 \\
São João de Meriti & 76.462 & 2.214 & 838 & 9.854 & 314 \\
\hline
\end{tabular}

Fonte: Censo demográfico, 1950

Elaboração: Juliana Luquez, a partir de SOARES, 1962

Soares (1962) também acrescenta que em 1945, Nova Iguaçu possui 500 construções licenciadas, em 1955 esse número sobe para $1860(+26 \%)$. A autora atribui a esse crescimento a abertura da Rodovia Presidente Dutra (trecho da BR-116) que giraria a roda da acumulação da citricultura (atividade econômica típica nos municípios do em torno da Baía de Guanabara) em direção às atividades fundiárias de loteamento e construção de empreendimentos residenciais e industriais na aglomeração metropolitana fluminense ${ }^{6}$. A função dormitório, como se convencionou chamar a dinâmica metropolitana de atração/influência entre um núcleo urbano principal e as cidades do seu em torno, é, em verdade, a consolidação do processo de estruturação urbano-industrial e berço da estruturação metropolitano-financeira.

Alguns bairros de Nova Iguaçu, Duque de Caxias e São Gonçalo destacam-se na dinâmica de revalorização do espaço na aglomeração fluminense, reforçando a fragmentação entre a Metrópole Rio e sua aglomeração metropolitana e realizando a dinâmica da produção do espaço em um movimento que se apreende pelos processos de periferização-espoliação-segregação. A periferização da classe trabalhadora, consolidando-se na expansão da industrial sob um modelo de acumulação contraditório entre o crescimento econômico e a pauperização absoluta ou relativa dos diversos segmentos da classe trabalhadora e aniquilando as formas históricas de apropriação social do espaço, incluindo a vida de bairro (SEABRA, 2003). A espoliação urbana, que vista 
pelas lentes do problema habitacional, constitui uma dimensão da exploração do trabalho e da exclusão cidadã. A segregação espacial, gestada nas relações sociais de produção e materializada como contradição urbana ${ }^{7}$ no processo de valorização diferencial da terra, que também caracteriza a especulação imobiliária na dinâmica de produção do espaço (KOWARICK, 2000).

É flagrante que a maior parte dos investimentos públicos é dirigida para as áreas onde vivem e trabalham as classes abastadas e que o processo de revalorização do espaço em áreas populares é uma via do movimento de reestruturação do espaço para maximizar a realização do capital e ampliar as condições gerais necessárias ao processo de acumulação. Por isso insistimos na formulação teórica que considera o processo de valorização como parte da exploração do trabalho e da exclusão cidadã da classe trabalhadora em relação à cidade que ela mesma produz. No caso das áreas urbanas em municipalidades periféricas essa produção da cidade é, por um lado, realizada pelas próprias mãos do trabalhador (residências autoconstruídas, bairros fundados por invasões e loteamentos clandestinos, ofertas populares ao acesso à terra) e, por outro lado, por sua capacidade de pressionar e obter do Estado, por meio de lutas sociais e reivindicações, os elementos indispensáveis à sobrevivência na cidade, estes também indispensáveis a reprodução da força de trabalho.

A engrenagem da reprodução do capital e de suas contradições não só expulsa a classe trabalhadora para longínquas áreas de possibilidades do modo de vida urbano (periferização) no momento da consolidação de uma estrutura de relações contidas na produção do espaço (espoliação), como também é capaz de reorientar o processo de valorização do espaço por meio da renovação das continuidades de seu movimento (segregação). Assim, estrutura-forma-função urbanas ganham um dinamismo no processo de produção do espaço que torna possível a afirmação de que as áreas periféricas ou os espaços populares, ontem produzidos pela classe trabalhadora, são, hoje, álibi de reestruturação do espaço para a sua revalorização, em um momento marcado pela iniciativa do Estado integralmente tomada pelos interesses privados (CHESNAIS, 1996). Outrora, "moradores espoliados e trabalhadores explorados" (KOVARICK, 2000, p. 35); ora, moradores segregados e trabalhadores precarizados, lançados à sorte da economia urbana terciária e sob o julgo da financeirização do capital.

Alguns bairros populares da Metrópole Rio, revalorizados na dinâmica imobiliária no contexto dos megaeventos esportivos (Copa do Mundo, em 2014 e Olimpíada, em 2016), como Marechal Hermes (9,59\%), Cascadura (7,56\%), Lins de Vasconcelos (6,7\%) e Abolição $(6,28 \%)^{8}$, todos localizados na zona norte carioca, foram ao longo do século XX ganhando estereótipos pejorativos, pois as ocupações consolidaram-se por uma população predominantemente operária. A reprodução da metrópole e a fragmentação do tecido urbano vão redefinir os estereótipos espaciais e consolidar o espaço da classe trabalhadora metropolitana nas áreas urbanas das municipalidades do em torno da Baía de Guanabara sob a influência da Metrópole Rio. Há, porém, de se destacar uma especificidade da metropolização fluminense: a dinâmica metropolitana sob a influência da Cidade do Rio de Janeiro, capital federal de 1889 a 1960ㅜ; e a dinâmica metropolitana sob a influência da Cidade de Niterói, capital estadual de 1835 a 1893 e de 1903 a 1974. Em 1975, a fusão do Estado da Guanabara, condição político-administrativa do Distrito Federal do Rio de Janeiro desde 1960, com o Estado do Rio de Janeiro, redefiniu e reorganizou os territórios fluminense e carioca, reconfigurando o Estado do Rio de Janeiro em torno da centralização e concentração da Cidade do Rio, a partir de então, a capital fluminense. Contraditoriamente, a fusão não impediu a cisão territorial fluminense e, ao contrário, reforçou-se com ela. 
A metropolização fluminense consolidou um espaço fragmentado, homogêneo e hierarquizado. Se a centralização do comando, da gestão e dos fluxos reforçou a posição da Cidade do Rio de Janeiro em relação à sua aglomeração metropolitana pós-fusão, também subordinou aos interesses do capital a reprodução das contradições urbanas no eixo metropolitano sob a influência de Niterói. Um exemplo desse movimento expressase na tabela 3 .

Tabela 3 - RMRJ: valor do $\mathrm{m}^{2}$ para compra de imóvel residencial considerando os municípios com maior dinâmica imobiliária (2015-2018)

\begin{tabular}{|c|c|c|}
\hline Município & Bairro & Valor médio do $\mathrm{m}^{2}(\mathrm{R} \$)$ \\
\hline \multirow{7}{*}{ Nova Iguaçu } & Centro & 5.545 \\
\hline & Metrópole & 4.376 \\
\hline & Rancho Novo & 4,107 \\
\hline & Caonze & 4.060 \\
\hline & Luz & 3.780 \\
\hline & Prata & 3.313 \\
\hline & Posse & 3.107 \\
\hline \multirow{6}{*}{ Duque de Caxias } & Jardim 25 de Agosto & 5.172 \\
\hline & Engenho do Porto & 4.043 \\
\hline & Centro & 3.855 \\
\hline & Jardim Primavera & 3.404 \\
\hline & Saracuruna & 2.365 \\
\hline & Doutor Laureano & 2.248 \\
\hline \multirow{6}{*}{ São Gonçalo } & Maria Paula & 4.358 \\
\hline & Centro & 4.125 \\
\hline & Barro Vermelho & 4.001 \\
\hline & Alcântara & 3.853 \\
\hline & Neves & 3.688 \\
\hline & Colubandê & 3.323 \\
\hline \multirow{9}{*}{ Rio de Janeiro } & Leblon & 22.346 \\
\hline & Ipanema & 20.218 \\
\hline & Lagoa & 18.039 \\
\hline & Barra da Tijuca & 10.327 \\
\hline & Centro & 8.354 \\
\hline & Méier & 5.483 \\
\hline & Taquara & 4.790 \\
\hline & Madureira & 3.820 \\
\hline & Campo Grande & 3.576 \\
\hline \multirow{8}{*}{ Niterói } & Charitas & 9.165 \\
\hline & Gragoatá & 8.844 \\
\hline & Icaraí & 7.889 \\
\hline & Camboinhas & 7.084 \\
\hline & Santa Rosa & 6.174 \\
\hline & Centro & 5.652 \\
\hline & Barreto & 5.024 \\
\hline & Fonseca & 4.341 \\
\hline
\end{tabular}

Fonte: Secovi Rio e VivaReal

Elaboração: Juliana Luquez.

Nos territórios municipais do Rio de Janeiro e de Niterói encontram-se as áreas mais valorizadas da aglomeração metropolitana fluminense. Nas quais observa-se uma 
forte e intensa dinâmica especulativa com valores que chegam a ser de 5 (cinco) a 10 (dez) vezes maiores que em outras áreas da região metropolitana. Os empreendimentos imobiliários implantados nos bairros nobres das cidades do Rio de Janeiro e de Niterói são tanto residenciais quanto comerciais respondem à demanda de mercado garantida por uma maior mobilidade social das classes mais abastadas e atendem à dinâmica de centralização e concentração das atividades urbanas nessas localidades.

A atividade imobiliária mantém relação estreita com a dinâmica de produção do espaço na aglomeração metropolitana do Rio de Janeiro, especialmente, a partir dos anos 1930. Até essa época a produção de moradias era uma exclusividade da iniciativa privada. O provimento de habitação pelo poder público, dos anos 1930 em diante, inaugura novos arranjos especulativos da atividade imobiliário. Por exemplo, em São Paulo, a cidade explode em periferias fundadas no trinômio loteamento-casa própria-autoconstrução (BONDUKI, 2013). No Rio de Janeiro, a explosão da cidade em direção aos subúrbios e freguesias rurais, deu-se pelo binômio trem-segregação proletária (FERNANDES, 2011). E, justamente, nesse movimento de expansão urbana, a atividade imobiliária encontrou seu limite e sua superação enquanto forma especulativa de produção do espaço.

\section{Considerações Finais}

A compreensão da produção contemporânea e da reestruturação dos espaços metropolitanos requer um esforço do entendimento da lógica espacial que está além de suas infraestruturas e materialidades. Especialmente porque este novo nexo da realidade virtual imprime à palavra próximo uma dimensão de significado pouco cogitado nas últimas décadas. A era da informação e a era da metropolização encontraram-se.

A capital fluminense, marcada historicamente pelas itinerâncias urbanas que viveu desde o século XVIII até atualmente: capital em várias escalas do poder políticoadministrativo do Brasil, destaca-se há mais de dois séculos pela sua função portuária e comercial, emergem nas suas paisagens urbanas toda a exuberância de sua natureza em meio a qual suas formas complexas e populares constituem o emaranhado espacial do urbano e de onde parte de sua economia ainda tem significativo valor de arrecadação, ou seja, nas atividades turísticas que ampliaram a prestação dos serviços voltados para este setor. Diante desse histórico, lhe batizaram de "Cidade Maravilhosa".

Se por um lado, o paradigma da desconcentração e descentralização das atividades urbanas nas metrópoles brasileiras, apontava interpretações de superação; diante do que foi posto até aqui as metrópoles ainda se mantém como centro de operações financeiras, sede de empresas multinacionais e cada vez mais integradas à rede urbana global, especialmente as metrópoles do eixo megalopolitano: Rio-São Paulo. Por outro, um olhar atento sobre os processos de concentração e centralização das atividades urbanas e do capital reforçam suas centralidades e contribuem para que a compreensão da produção contemporânea do espaço se dê também pela lógica da imaterialidade que tem se mostrado muito eficaz na reconfiguração territorial das cidades e dos arranjos regionais urbanos.

Finalmente, para o debate atual sobre produção contemporânea do espaço, a preocupação ao considerar os processos espaciais a partir de suas diferentes dimensões e níveis na realidade complexa da atual fase de urbanização, evidencia os reordenamentos territoriais que incorporam espaços longínquos e ampliam as fossas da fragmentação entre os mais próximos, contudo não os desintegrando, ao contrário, fortalecendo uma dinâmica de homogeneização que permite a compreensão da presença da metrópole nas ausências de seu entorno. 


\section{Notas}

1 - Com o termo Metrópole Rio referimo-nos a classificação dada a Cidade do Rio de Janeiro mediante sua polarização e influência em relação as cidades de seu em torno. Distanciamo-nos, assim, da definição utilizada por alguns autores fluminenses (NATAL, 2003; SOUZA, 2018) e pela Câmara Metropolitana de Integração Governamental do Rio de Janeiro $(2011$; 2015) que se referem a Metrópole Rio como sendo o conjunto da Cidade do Rio e sua região de influência.

2 - É mister destacar que a natureza das relações sociais de produção constitui-se no principal fator de diferenciação entre as dinâmicas econômicas do Rio de Janeiro e de São Paulo. No Rio de Janeiro, essas relações baseavam-se em uma lógica escravocrata, sendo os exemplos mais claros, a organização do trabalho nos sistemas produtivos do médio Vale do Paraíba e a consolidação de núcleos favelados e periféricos na metrópole e no seu em torno (CAMPOS, 2005). Em São Paulo, as relações de produção assalariadas permitiram novos elementos, sob outras lógicas, à organização do trabalho e à recomposição territorial. Tais elementos, todos necessários, a essa nova estruturação da produção: novas relações socais de produção e de reprodução (MARTINS, 2010).

3 - Fundação Centro Estadual de Estatísticas, Pesquisas e Formação de Servidores Públicos do Rio de Janeiro (CEPERJ).

4 - Para Lencioni "o processo de metropolização do espaço se expressa na intensificação e multiplicidade dos fluxos de pessoas, mercadorias e informações, bem como pelo crescimento do número de cidades conurbadas, onde não se distingue muito bem, na continuidade da área construída, o limite municipal de cada uma delas. E, também, pela expansão territorial do aglomerado metropolitano e pela extensão e densificação territorial da concentração das infraestruturas.” (LENCIONI, 2011, p. 136).

5 - Texto original: « l'espace ait pris dans le mode de production atuel et dans la société en acte telle qu'elle est, une sorte de realité propre, au même titre e dans le même processus global que la marchandise, l'argent, le capital, mais de façon distincte » (LEFEBVRE, 2000, p. 35).

6 - Sobre esse assunto, tratamos em "Evolução e estruturação urbanas de São Gonçalo: do final do século XIX à segunda guerra mundial", 2013.

7 - Para Kowarick as contradições urbanas se dão em decorrência de os "investimentos públicos em bens de consumo coletivo [serem] tradicionalmente realizados em prejuízo da grande massa dos trabalhadores" (KOWARICK, 2000, p. 23).

8 - Dados divulgados pelo Sindicato da Habitação (Secovi Rio) e pelo portal imobiliário Viva Real em relação a 2015.

9 - A Cidade do Rio de Janeiro foi, sucessivamente, capital da Colônia Portuguesa do Estado do Brasil, de 1621 a 1815, do Reino Unido de Portugal, Brasil e Algarves entre 1815 a 1822, do Império do Brasil, de 1822 a 1889 e da República do Brasil até 1960, quando a sede do governo foi transferida para Brasília.

\section{Bibliografia}

ABREU, Maurício de. Evolução Urbana do Rio de Janeiro. Rio de Janeiro: IPP, 2008. AGLIETTA, Michel. Segunda Parte. Cap. IV - Concentración y centralización del Capital. Itens: Definición y causas de la concentración del capital. 1.1. Concentración y centralización del capital industrial. In: Regulación y Crisis del Capitalismo. $3^{\mathrm{a}}$ ed. México: Siglo Veintiuno Edotores, 1986. p. 192-197.

BONDUKI, Nabil. Origens da habitação social no Brasil: arquitetura moderna, lei do inquilinato e difusão da casa própria. 6 ed. São Paulo: estação Liberdade, 2013.

CAMPOS, Andrelino. Do quilombo à favela: a produção do espaço criminalizado no Rio de Janeiro. Rio de Janeiro: Bertrand, 2005.

CHESNAIS, François. A mundialização do capital. São Paulo, Xamã, 1996.

DAVIDOVICH, Fany Rachel. Estado do Rio de Janeiro: Singularidades de um Contexto Territorial. In: Anais do VIII Encontro Nacional da ANPUR. Porto Alegre, 1999. Disponível em: <http://unuhospedagem.com.br/revista/rbeur/index.php/anais/article/view/2002/1965>. Metrópole e Território: metropolização do espaço no Rio de Janeiro. Cadernos Metrópole n. 6, $2^{\circ}$ sem. Rio de Janeiro, 2001. 
. O Entorno da Região Metropolitana do Rio de Janeiro, hipóteses considerações. In: Anais do IX Encontro Nacional da ANPUR. Rio de Janeiro, ANPUR, 2001. Disponível em: <http://unuhospedagem.com.br/revista/rbeur/index.php/anais/article/view/2164/2117> FERNANDES, Nelson da Nóbrega. O rapto ideológico da categoria subúrbio: Rio de Janeiro 1858-1945. Rio de Janeiro: Apicuri, 2011.

FREITAG, Barbara. Capitais migrantes e poderes peregrinos: o caso do Rio de Janeiro. Campinas, SP, 2009.

GEIGER, Pedro Pinchas. Urbanização e industrialização na orla Oriental da Baía de Guanabara. Revista Brasileira de Geografia, Rio de Janeiro: IBGE, v. 18, n. 4, out./dez. p. 47-74, 1956.

KOWARICK, Lúcio. Escritos urbanos. São Paulo: Editora 34, 2000.

LEFEBVRE, Henri. A Revolução Urbana. Belo Horizonte: Ed. UFMG, 2008.

LENCIONI, Sandra. Concentração e Centralização das Atividades Urbanas: uma perspectiva multiescalar. Reflexões a partir do caso de São Paulo. Revista de Geografia Norte Grande, v. 39, p. 7-20, 2008. Disponível em: <http://www.scielo.cl/scielo.php?pid=S0718-34022008000100002\&script=sci_arttext>

. Metropolização do Espaço e a Constituição de Mega-Regiões. II Simpósio Internacional Metropolização do Espaço, Gestão Territorial e Relações Urbano-Rural (2014). Disponível em: http://media.wix.com/ugd/46d988_1bf83941796f420b88ff343ec71d6f80.pdf

Reestruturação Urbano-Industrial no Estado de São Paulo: a Região da Metrópole Desconcentrada. Espaço e Debates, São Paulo, no 38, p. 54-61, 1994. MARICATO, Ermínia. O impasse da política urbana no Brasil. Petrópolis: Vozes, 2011.

Para entender a crise urbana. São Paulo: Expressão Popular, 2015.

MARTINS, José de Souza. O cativeiro da terra. 9. ed. São Paulo: Contexto, 2010.

MARX, Karl. O capital: crítica da economia política. Livro I: O processo de produção do capital. São Paulo: Boitempo, [1867]2013.

ROLNIK, Raquel; FRÚGOLI, Heitor. Reestruturação Urbana da Metrópole Paulista: a Zona Leste como território de rupturas e permanências. In: Cadernos Metrópole, v. 6, São Paulo: 2001. Disponível em: <http://revistas.pucsp.br/index.php/metropole/article/view/9268/6874>.

SEABRA, Odette. Urbanização e fragmentação: cotidiano e vida de bairro na metamorfose da cidade em metrópole, a partir das transformações do bairro do Limão. Tese de Livre Docência (Geografia Humana) - Faculdade de Filosofia, Letras e Ciências Humanas, Universidade de São Paulo, São Paulo, 2003.

SOARES, Maria Therezinha de Segadas. Nova Iguaçu: absorção de uma célula urbana pelo Grande Rio de Janeiro. Revista Brasileira de Geografia, Rio de Janeiro: IBGE, v. 24, n. 2, abr./jun. p. 3-104, 1962.

SOBRAL, Bruno Leonardo Barth. Crise e ciclo: limites à capacidade de um crescimento econômico sustentado na periferia metropolitana do Rio de Janeiro diante do ciclo recente de grandes investimentos. Brasília/Rio de Janeiro: IPEA, 2015a. (Texto para Discussão 2143).

O necessário, o possível e o impossível: uma leitura do papel das políticas públicas diante dos limites à coordenação de grandes investimentos na periferia metropolitana fluminense. Brasília/Rio de Janeiro: IPEA, 2015b. (Texto para Discussão 2154). 
$\overline{\text { VIANA, Juliana Nazare Luquez. Evolução e estruturação urbanas de São Gonçalo: do }}$ final do século XIX à segunda Guerra Mundial. Dissertação de Mestrado (Geografia) Instituto Geociências, Universidade Federal Fluminense, Niterói, 2013.

Rupturas e continuidades. A produção do espaço e o processo de reestruturação: um olhar a partir de São Gonçalo, Região Metropolitana do Rio de Janeiro. 2019. 312 f. Tese (Doutorado em Geografia Humana) - Faculdade de Filosofia, Letras e Ciências Humanas, Universidade de São Paulo, São Paulo, 2018. 